\title{
Metaclassifications for caesarian section classification dataset data set
}

\author{
Dr.G.Ayyappan, \\ Associate Professor, Bharath Institute of Higher Education and Research,Chennai \\ ayyappangmca@gmail.com
}

\begin{abstract}
This research work presents a decision making of healthcare operational system by using machine learning classifiers algorithm to predict the decision making in comparison to the actual decision making. This model may help to doctor for making the best decisions. This model helps us to predict surgery. This study explains utilization of machine learning algorithms in determination of medical operation methods. The results show that Bagging, logitBoost and Multiclassclassifier for this case study generates highest accuracy of $\mathbf{4 8 . 7 5 \%}$.
\end{abstract}

\section{INTRODUCTION}

Machine learning in today's healthcare is unavoidable. Optimists predict that machine learning and artificial intelligence will diagnose disease better and earlier, treat illness more precisely and engage patients more efficiently in future healthcare. Recent advancements in machine learning have demonstrated that machine learning can create algorithms that perform on par with human physicians.

Today's healthcare needs effective methods and research methodologies to save lives, reduce the cost of the healthcare services and early discoveries of contagious diseases. Machine learning techniques can enable healthcare organizations to predict trends in patient conditions and their behaviors. Recent findings in healthcare sector led to the collection of large size of rich data. McKinsey estimates that big data and machine learning could generate a value of $\$ 100$ billion annually based on better decision making, optimized innovation and improved efficiency of clinical trials. Extracting useful knowledge and regularities from datasets can provide a major opportunity for practical use to improve healthcare. Knowledge acquired in this manner can be used to predict trends of patient's condition in shortest possible time and reduce the cost of healthcare services.

In recent years instances in healthcare such as medical image processing and analyzing, predicting healthcare operational decisions, dosage trials for intravenous tumor treatment detection and management of prostate cancer.

In this paper organizes section one has related works and brief introduction of this fields, section two presents Materials and Methods, the section three describes results and discussions and the section four presents conclusion.

\section{MATERIALS AND METHODS}

In this section presents the materials and methods of this research work. Here the dataset borrowed from Caesarian Section Classification Dataset Data (https://archive.ics.uci.edu/ml/datasets/Caesarian+Section+Classification+Dataset\#). In this dataset contains information about caesarian section results of 80 pregnant women with the most important characteristics of delivery problems in the medical field. The below table describes the attributes detail in this dataset. 
Table 1 Attribute Description in the dataset

\begin{tabular}{|c|c|c|c|c|}
\hline S.No & $\begin{array}{c}\text { Name of the } \\
\text { Attribute }\end{array}$ & Values of the Attribute & $\begin{array}{c}\text { Characteristics } \\
\text { of Attribute }\end{array}$ & $\begin{array}{c}\text { Meaning of the } \\
\text { Attribute }\end{array}$ \\
\hline 1 & Age & $\begin{array}{c}22,26,28,27,32,36,33,23, \\
20,29,25,37,24,18,30,40, \\
31,19,21,35,17,38\end{array}$ & Numeric & $\begin{array}{c}\text { Pregnant ladies age } \\
\text { between } 22 \text { to } 38\end{array}$ \\
\hline 2 & $\begin{array}{c}\text { Delivery } \\
\text { Number }\end{array}$ & $1,2,3,4$ & Numeric & Delivery Number 1 to 4 \\
\hline 3 & Delivery time & $0,1,2$ & Numeric & $\begin{array}{c}0=\text { timely }, \\
1=\text { premature } \\
2=\text { latecomer }\end{array}$ \\
\hline 4 & Blood of & $2,1,0$ & Numeric & $\begin{array}{c}0=\text { low }, \\
1=\text { normal }, \\
2=\text { high }\end{array}$ \\
\hline 5 & Pressure & & & $\begin{array}{c}0=\text { apt, } \\
1=\text { inept }\end{array}$ \\
\hline 6 & Caeart Problem & 1,0 & Numeric & $\begin{array}{c}0 \text { No, } \\
1=\text { Yes }\end{array}$ \\
\hline
\end{tabular}

In this research work applied in weka 3.8.3 version for meta classifications method were applied to calculate for predicting caesarian section operational decisions. In this research work considers name of the attribute Blood of Pressure ‘0' represents 'low' ‘1' represents ‘normal' and '2' represents 'high' in class.

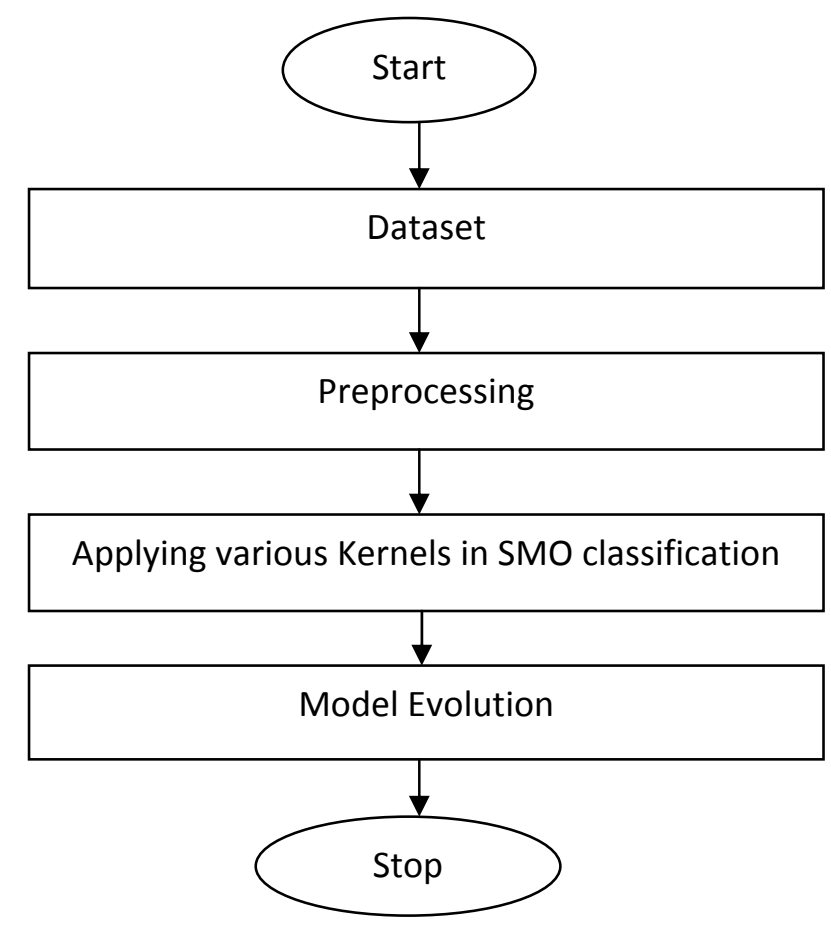

Figure 1 Architecture of Proposed method

\section{RESULTS AND DISCUSSIONS}

Machine learning has great importance for area of healthcare, and it represents comprehensive process that demands thorough understanding of needs of the healthcare organization regarding operational decision making. In this study, the machine learning techniques was used for selecting the most significant features to be used in predicting caesarian section accurately. In this work variousmachine learning meta algorithms namely AdaboostM1, Bagging, RandomCommitte, logitBoost and Multiclassclassifierwere used to calculate for predicting caesarian section operational decisions. 
Table 2 Accuracy levels of Caesarian Section Classification Dataset Data Set

\begin{tabular}{|c|c|c|}
\hline S.No & Mata Classification & Accuracy level \\
\hline 1 & AdaboostM1 & $42 \%$ \\
\hline 2 & Bagging & $48.75 \%$ \\
\hline 3 & RandomCommitte & $38.75 \%$ \\
\hline 4 & logitBoost & $48.75 \%$ \\
\hline 5 & Multiclassclassifier & $48.75 \%$ \\
\hline
\end{tabular}

In this work various machine learning algorithms namely AdaboostM1 has 42\%,Bagging has 48.75\%, RandomCommitte has 38.75\%,logitBoost has $48.75 \%$ and Multiclassclassifier has $48.75 \%$ were calculated for predicting caesarian section operational decisions.

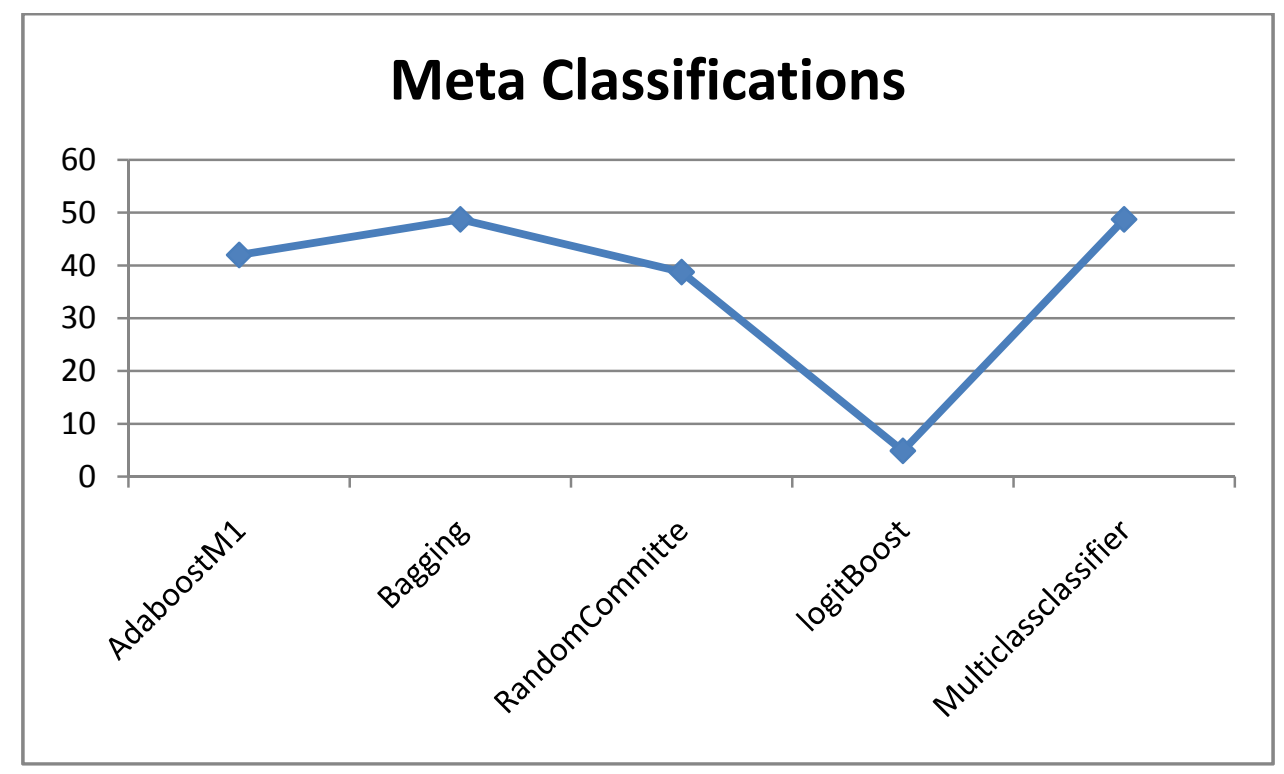

Figure 2 Accuracy levels of various classifications

\section{CONCLUSION}

The experiment results show that Bagging, logitBoost and multiclassclassifierachieved the best accuracy rates by predicting 48.75 cases correctly compare than other models.So, this research work recommended for decision making based on the Bagging, logitBoost and multiclassclassifierclassifications.

\section{REFERENCES}

[1] (PDF) Performance Evaluation of Supervised Machine Learning Classifiers for Predicting Healthcare Operational Decisions. Available https://www researchgatenet/publication/329515048_Performance_Evaluation_of Supervised_Machine_Learning_Classifiers_for_Pr: edicting_Healthcare_Operational_Decisions [accessed Jan 06 2019].

[2] Boris Milovic, MilanMilovic. Prediction and Decision Making in Health Care using Data Mining, International Journal of Public Health Science (IJPHS), Vol. 1, No. 2, December 2012, pp. 69 78

[3] Fayyad, U., Shapiro, G. P., \& Smyth, P. (1996). From Data Mining to Knowledge Discovery in Databases. American Association for Artificial Intelligence, 37-54.

[4] H. Jiawei and K. Micheline, Data Mining: Concepts and Techniques, vol. 2, Morgan Kaufmann Publishers, 2006.

[5] Candelieri, A., Dolce, G., Riganello, F., \& Sannita, W. G. (2011). Data Mining in Neurology. In Knowledge Oriented Applications in Data Mining (pp. 261-276). InTech.

[6] Brady E. Hamilton, Ph.D.; Joyce A. Martin, M.P.H.; and Stephanie J. Ventura, M.A., Division of Vital Statistics, Births: Preliminary Data for 2007, National Vital Statistics Report. [7] Births: Provisional Data for 2017 USA. CDC. May 2018. Retrieved 18 May 2018.

[7] World Health Organization (WHO) statement "Should there be a limit on Caesareans?". BBC News. 30 June 2010.

[8] Andrew Simm, Darly Mathew, Caesarian section: techniques and complications, Obstetrics, Gynaecology \& Reproductive Medicine, Volume 18, Issue 4, April 2008, Pages 93-98.

[9] FarhadSoleimanianGharehchopogh, PeymanMohammadi, ParvinHakimi, Application of Decision Tree Algorithm for Data Mining in Healthcare Operations: A Case Study, International Journal of Computer Applications (0975 - 8887) Volume 52 - No. 6, August 2012,Pages 21-26. 